\title{
Suppression of HDAC2 by sodium butyrate alleviates apoptosis of kidney cells in db/db mice and HG-induced NRK-52E cells
}

\author{
YI DU, GANG TANG and WEIJIE YUAN \\ Department of Nephrology, Shanghai General Hospital, Shanghai Jiao Tong University School of Medicine, \\ Shanghai 200080, P.R. China
}

Received July 23, 2019; Accepted October 18, 2019

DOI: $10.3892 /$ ijmm.2019.4397

\begin{abstract}
Butyrate is short-chain fatty acid, which is produced by intestinal microbiota metabolizing dietary fibers. Butyrate participates in various physiological processes predominantly by activating G-coupled-receptors, inhibiting histone deacetylases (HDACs) and serving as an energy substrate. Previous studies have shown that butyrate plays a protective role in diabetic nephropathy (DN); however, the exact mechanism remains unclear. The present study identified that providing sodium butyrate $(\mathrm{NaBu})$ by gavage relieved renal damage and apoptosis in $\mathrm{db} / \mathrm{db}$ mice, which is a widely used type $2 \mathrm{DN}$ model. In vitro, $\mathrm{NaBu}$ suppressed high glucose (HG)-induced apoptosis in normal rat kidney tubular epithelial (NRK-52E) cells. Of the eleven HDACs (HDAC1-11) studied, only the mRNA expression of HDAC2 was attenuated by $\mathrm{NaBu}$ in NRK-52E cells under the HG condition. Overexpression of HDAC2 offset the anti-apoptotic effect of $\mathrm{NaBu}$. $\mathrm{NaBu}$ also suppressed $\mathrm{HG}$-induced oxidative stress. Additionally, $\mathrm{H}_{2} \mathrm{O}_{2}$ induced an upregulation of HDAC2 in NRK-52E cells, while $\mathrm{NaBu}$ inhibited this process. Mechanistically, $\mathrm{NaBu}$ acted as an antioxidant in HG-induced NRK-52E cells and suppressed HG-induced apoptosis of NRK-52E cells through inhibiting HDAC 2 by virtue of its anti-oxidative property.
\end{abstract}

\section{Introduction}

Diabetes is a devastating disease and is one of the main causes of chronic kidney disease. Lack of effective treatments results in a number of patients developing diabetic nephropathy (DN) (1).

Correspondence to: Professor Weijie Yuan, Department of Nephrology, Shanghai General Hospital, Shanghai Jiao Tong University School of Medicine, 100 Haining Road, Shanghai 200080, P.R. China E-mail: ywj4168@163.com

Abbreviations: SCFAs, short-chain fatty acids; UACR, urinary albumin to creatinine; HDAC, histone deacetylase; STZ, streptozotocin; DN, diabetic nephropathy; TSA, trichostatin A; $\mathrm{NaBu}$, sodium butyrate; ROS, reactive oxygen species; $\mathrm{HG}$, high glucose; $\mathrm{H}_{2} \mathrm{O}_{2}$, hydrogen peroxide

Key words: sodium butyrate, histone deacetylase 2, NRK-52E cells, apoptosis, diabetic nephropathy, oxidative stress
Recent studies have demonstrated a close relationship between intestinal microbiota and the occurrence and development of diabetes $(2,3)$ A study by Koh and Rowling (4) indicated that a high fiber diet serves a protective role in the progression of diabetes and DN. Short-chain fatty acids (SCFAs) are one of the major metabolites of the microbiota-mediated fiber fermentation process in the gut (5).

Butyrate is a SCFA and has been demonstrated to play a protective role in kidney disease $(6,7)$. Administration of sodium butyrate $(\mathrm{NaBu})$ rescues kidney function in acute kidney injury by reducing apoptosis, increasing autophagy and inhibiting reactive oxygen species (ROS) production (6). $\mathrm{NaBu}$ also attenuates the increase in creatinine, decreases mediators of inflammation and decreases tubular damage in contrast-induced nephropathy in vivo (7).

The function of butyrate in diabetes has also been studied. $\mathrm{Xu}$ et al (8) found that oral $\mathrm{NaBu}$ administration significantly alleviates inflammation in $\mathrm{db} / \mathrm{db}$ mice by correcting intestinal microecological disorder and protecting intestinal barrier integrity. Additionally, intraperitoneal injection of $\mathrm{NaBu}$ alleviates streptozotocin (STZ)-induced mice pancreatic injury and inflammatory responses by downregulating the $\mathrm{NF}-\kappa \mathrm{B}$ pathway (9).

Protective effects of butyrate on DN have also been reported. Administration of $\mathrm{NaBu}(500 \mathrm{mg} / \mathrm{kg} /$ day $)$ by intraperitoneal injection ameliorates fibrosis and inflammation in the kidneys of STZ-induced diabetic rats (10). Dong et al (11) also reported that a diet containing $\mathrm{NaBu}(5 \mathrm{~g} / \mathrm{kg} /$ day $)$ alleviates renal dysfunction and mesangial matrix expansion in STZ-induced diabetic mice. The apoptosis of renal cells, particularly renal tubular epithelial cells, is an important factor in the progression of DN (12). To the best of our knowledge, whether butyrate can protect renal tubular epithelial cells from high glucose (HG)-induced apoptosis has not been studied. Therefore, the aims of the present study were to evaluate the function of $\mathrm{NaBu}$ in the apoptosis of renal cells in $\mathrm{db} / \mathrm{db}$ mice, to investigate the function of $\mathrm{NaBu}$ in $\mathrm{HG}$-induced apoptosis of NRK-52E cells, and to discuss the specific mechanisms.

\section{Materials and methods}

Animals. In total, 20 male $\mathrm{db} / \mathrm{db}$ mice and 10 male $\mathrm{db} / \mathrm{m}$ non-diabetic control mice (age, 4 weeks; weight, $20 \mathrm{~g}$ ) were purchased from the Nanjing Institute of Model Animals. All 
mice were kept in the animal center of Shanghai General Hospital at $24^{\circ} \mathrm{C}, 40-70 \%$ humidity, with a $12 / 12 \mathrm{~h}$ light/dark cycle and air exchange. Mice had access to food and water ad libitum. At 8 weeks old, $\mathrm{db} / \mathrm{m}$ mice were randomly divided into control $(n=5)$ and control $+\mathrm{NaBu}(n=5)$ groups, and $\mathrm{db} / \mathrm{db}$ mice were randomly divided into diabetic (DM; $n=8)$, and diabetic $+\mathrm{NaBu}(\mathrm{DM}+\mathrm{NaBu} ; \mathrm{n}=12)$ groups. Mice in the control $+\mathrm{NaBu}$ and $\mathrm{DM}+\mathrm{NaBu}$ groups were administered $1 \mathrm{~g} / \mathrm{kg} \mathrm{NaBu}$ by oral gavage once a day from Monday to Friday. Mice in the other two groups were given the same volume of distilled water. The mice were euthanized by intraperitoneal injection of sodium pentobarbital $(100 \mathrm{mg} / \mathrm{kg})$ after 12 weeks of treatment. No mouse died prior to euthanasia. Death of the mice was verified by confirmation of cardiac arrest. During the experiments, the health and behavior of mice were monitored daily. Blood glucose levels were recorded on Mondays at weeks 6, 8, 12, 16 and 20 after birth. Urine was collected on Monday morning of week 20. Urinary albumin and creatinine were detected on a fully automatic biochemical analyzer (Rayto Life and Analytical Sciences Co., Ltd.). The ratio of urinary albumin to creatinine (UACR) was calculated using Excel 2016 (Microsoft Corporation).

All animal-related experiments were approved by the Institutional Animal Care and Use Committee of Shanghai General Hospital and were in compliance with the Guide for the Care and Use of Laboratory Animals and the U.S. National Institutes of Health. The project number is 2019DW001.

Cell culture. NRK52E cells were purchased from the China Center for Type Culture Collection, and were cultured in Dulbecco's modified Eagle's medium (DMEM; HyClone; GE Healthcare; $5.6 \mathrm{mmol} / \mathrm{l}$ glucose) with $5 \%$ fetal bovine serum (FBS; Gibco; Thermo Fisher Scientific, Inc.) and $100 \mathrm{U} / \mathrm{ml}$ penicillin/streptomycin (NCM Biotech) at $37^{\circ} \mathrm{C}$ with $5 \% \mathrm{CO}_{2}$. Prior to treatment, cells were cultured in serum-free media for 10-12 h. Then, cells were divided into the following experimental groups: i) Normal glucose group, DMEM with $5.6 \mathrm{mM}$ glucose for $48 \mathrm{~h}$; ii) $\mathrm{HG}$ group, DMEM with $25 \mathrm{mM}$ glucose for $48 \mathrm{~h}$; iii) $\mathrm{NaBu}$ or TSA intervention groups $(\mathrm{HG}+\mathrm{NaBu}$ or $\mathrm{HG}+\mathrm{TSA})$, high glucose DMEM with additional $\mathrm{NaBu}(0.1$, 0.5 or $1.0 \mathrm{mmol}$ ) or TSA (cat. no. HY-15144; MedChemExpress; $0.1 \mu \mathrm{mol})$ for $48 \mathrm{~h}$. Cells were treated at $37^{\circ} \mathrm{C}$.

Transfection with pEGFP-C1-HDAC2 plasmid. pEGFP-C1HDAC2 plasmid and the corresponding empty vector pEGFP-C1 were purchased from Shanghai Gene Pharma Co., Ltd. The NRK-52E cells were seeded into 6-well plates in Opti-MEMR medium (Gibco; Thermo Fisher Scientific, Inc.) and transfected with plasmids using Lipofectamine ${ }^{\circledR} 2000$ (Invitrogen; Thermo Fisher Scientific, Inc.), according to the manufacturer's protocol. The final concentration of plasmids was $1.25 \mathrm{ng} / \mu \mathrm{l}$. Treatments were applied to cells after $6 \mathrm{~h}$.

Immunohistochemistry. Kidneys were harvested post-mortem and fixed in $4 \%$ paraformaldehyde at $4{ }^{\circ} \mathrm{C}$ overnight, embedded in paraffin and cut into $5-\mu \mathrm{m}$ thick sections. Following heat treatment at $96^{\circ} \mathrm{C}$ with citrate solution for antigen retrieval and blocking with $3 \%$ bovine serum albumin (cat. no. A8020; Solarbio Science \& Technology Co., Ltd.) at room temperature for $30 \mathrm{~min}$, sections were incubated with primary antibody against HDAC2 (1:500; cat. no. GB11371; Wuhan Servicebio Technology Co., Ltd.) at $4^{\circ} \mathrm{C}$ overnight. Following incubation with goat anti-rabbit secondary antibody (1:200; cat. no. GB23303; Wuhan Servicebio Technology Co., Ltd.) at room temperature for $50 \mathrm{~min}$, slides were treated with a 3,3'-diaminobenzidine kit (cat. no. K5007; Dako; Agilent Technologies, Inc.). Images were captured using a light microscope (magnification, $\mathrm{x} 40$ ).

Western blot analysis. Proteins of the mice kidneys and NRK-52E cells were isolated using RIPA lysis buffer (Beyotime Institute of Biotechnology) containing PMSF (Beyotime Institute of Biotechnology) and phosphatase inhibitors (NCM Biotech). The quality and concentration of protein were detected using NanoDrop (Thermo Fisher Scientific, Inc.). Protein samples mixed with loading buffer were denatured by boiling for $10 \mathrm{~min}$ and then $40 \mu \mathrm{g}$ protein was added to each lane and separated by $10 \%$ SDS-PAGE for HDAC2 or $12.5 \%$ SDS-PAGE for Bcl-2 and Bax. Subsequently, the proteins were transferred onto a polyvinylidene difluoride membrane. Membranes were incubated with primary antibodies against the following at $4{ }^{\circ} \mathrm{C}$ overnight: HDAC2 (1:1,000; cat. no. 2540S; Cell Signally Technology, Inc.), Bcl-2 (1:1,000; cat. no. abs131701; Absin Bioscience Inc.), Bax (1:1,000; cat. no. 14796S; Cell Signaling Technology, Inc.) and $\beta$-actin (1:1,000; cat. no. abs119600; Absin Bioscience Inc.). Subsequently, the membranes were incubated with goat anti-rabbit secondary antibody (1:10,000; cat. no. abs20002; Absin Bioscience Inc.) at room temperature for $2 \mathrm{~h}$. Protein bands were visualized using ECL reagents (NCM Biotech), and blots were quantified with Image-pro Plus 6.0 (Media Cybernetics, Inc.).

RNA extraction and reverse transcription-quantitative $P C R$ $(R T-q P C R)$. TRIzol ${ }^{\circledR}$ reagent (Invitrogen; Thermo Fisher Scientific, Inc.) was used to isolate total RNA from NRK-52E cells. Samples that contained $500 \mathrm{ng}$ total RNA were reverse transcribed with Prime Script ${ }^{\mathrm{TM}}$ RT Master mix kit (Takara Bio, Inc.) and qPCR was performed with the TB Green ${ }^{\mathrm{TM}}$ Premix Ex $\mathrm{Taq}^{\mathrm{TM}}$ kit (Takara Bio, Inc.), according to the manufacturers' protocols. The thermocycling conditions were as follows: $95^{\circ} \mathrm{C}$ for $30 \mathrm{sec}$, followed by 40 cycles of $95^{\circ} \mathrm{C}$ for $5 \mathrm{sec}$ and $60^{\circ} \mathrm{C}$ for $30 \mathrm{sec}$. The primers are listed in Table I. GADPH was used as the reference gene. The data were quantified using the $2^{-\Delta \Delta \mathrm{Cq}}$ method (13).

Quantification of apoptosis by flow cytometry. Following trypsinization, cells were collected and washed with PBS twice. The cells were then resuspended and stained with Annexin V-FITC for $15 \mathrm{~min}$ and propidium iodide for 5 min (BestBio Company). Apoptosis was quantified using a BD LSR flow cytometer (BD Biosciences). The BD Accuri ${ }^{\mathrm{TM}}$ C6 software (version 1.0.264.21; BD Biosciences) was used for analysis. The apoptosis of NRK-25E cells was also detected by flow cytometry at 12, 24 and $48 \mathrm{~h}$ after treatment.

Assay of caspase-3 activity. A caspase-3 activity assay kit (cat. no. BB-4106; BestBio Company) was used to detect the activity of caspase-3 in different groups, according to the manufacturer's protocol. A multimode reader (Thermo Fisher 
Table I. Primer sequences for reverse transcription-quantitative PCR.

Primer sequence (5'-3')

\begin{tabular}{lll}
\cline { 2 - 3 } Gene & \multicolumn{1}{c}{ Forward } & \multicolumn{1}{c}{ Reverse } \\
\hline HDAC1 & ATGAAGCCTCACCGAATCCGAATG & CTTGGTCATCTCCTCAGCGTTGG \\
HDAC2 & CGAGCATCAGACAAGCGGATAGC & AGCGACATTCCTACGACTCCTTC \\
HDAC3 & CCAAGACCGTGGCGTATTTC & CTCAGAATGGAAGCGGCACA \\
HDAC4 & GGCTTCCTTGTGGTGGTGTTGG & TGTACTCTCCTCGGCATGGTGTC \\
HDAC5 & GCAGCAGCACCAGCAGTTCC & CCGTCAGCTCCTCCTCTGTCTC \\
HDAC6 & AGAAGCACCGCATTCAGAGGATTC & GCCAGAACCGACCATGCTCATAG \\
HDAC7 & AGGAGGTGCGGTGGTGTTGG & GAGCGGATGGCATTGAGGTTGG \\
HDAC8 & GTATGTCCTTCAGTGGCAGTTGGC & CGGTCAAGTATGTCCAGCAACGAG \\
HDAC9 & CTGGAGAAACCTGCCAAGTATG & GGTGGAAGAATGGGAGTTGCT \\
HDAC10 & TTCCAGCCTGACATGGTGTTGATG & TCCGAAGCATTGCAGCCAAGAG \\
HDAC11 & GGCACGAGCGAGACTTCATGG & CAACTCCACCTTCCGCCTGATG \\
GADPH & CTGGAGAAACCTGCCAAGTATG & GGTGGAAGAATGGGAGTTGCT \\
\hline
\end{tabular}

HDAC, histone deacetylase.

Scientific, Inc.) was used to measure the absorbance at $405 \mathrm{~nm}$ of different samples.

HDAC activity. NE-PER nuclear and cytoplasmic extraction reagents (cat. no. 78833; Pierce; Thermo Fisher Scientific, Inc.) were used to separate the nuclear and cytoplasmic components. The cytoplasmic extraction reagents I and II and nuclear extraction reagent were added to the cells sequentially. Following oscillation and centrifugation, the supernatant (nuclear extract) was collected. Diluted nuclear extract was mixed with HDAC assay buffer and HDAC colorimetric substrate (cat. no. K331; BioVision). Following incubation at $37^{\circ} \mathrm{C}$ for $1 \mathrm{~h}$, lysine developer was used to terminate the reaction. Activities of HDAC in different samples were reflected by the optical density values at $405 \mathrm{~nm}$, which were detected by a multimode reader (Thermo Fisher Scientific, Inc.).

HDAC2 activity. A colorimetric assay kit (cat. no. GMS50082; Genmed Scientifics, Inc.) was used to assess HDAC2 activity. Nuclear extract was mixed with colorimetric substrate. The substrate is deacetylated and produces a fluorophore following treatment with aminopeptidase. The absorbance at $405 \mathrm{~nm}$ of each group was measured by a multimode reader (Thermo Fisher Scientific, Inc.).

TUNEL assay. A POD kit (cat. no. 11684817910; Roche Diagnostics) was used to measure TUNEL-positive apoptotic cells in tissue sections. Kidneys were harvested post-mortem and fixed in $4 \%$ paraformaldehyde at $4{ }^{\circ} \mathrm{C}$ overnight, embedded in paraffin and cut into $5-\mu \mathrm{m}$ thick sections. Renal paraffin sections $(5-\mu \mathrm{m})$ were de-waxed and incubated with protease $\mathrm{K}$. Subsequently, the sections were treated with the TUNEL reaction mixture and incubated for $60 \mathrm{~min}$ in a water bath at $37^{\circ} \mathrm{C}$. DAPI (Beyotime Institute of Biotechnology) was used to stain nuclei. Images were obtained using a fluorescence microscope (magnification, x20). Five fields of vision were randomly selected for each slice.
ROS assay. A ROS detection kit (cat. no. BB-47053; BestBio Company), which detects ROS by the DCFH-DA method, was used. DCFH-DA crosses cell membranes freely. When DCFH-DA enters cells, it is hydrolyzed by intracellular enzymes to non-fluorescent DCFH, which can't cross the cell membrane. In the presence of ROS, DCFH can be oxidized to highly fluorescent DCF (14). The level of ROS in cells was determined by detecting the fluorescence of DCF with a confocal microscope (magnification, x63) and flow cytometer. The BD Accuri ${ }^{\mathrm{TM}}$ C6 software (version 1.0.264.21; BD Biosciences.) was used for analysis.

Superoxide dismutase (SOD) and lactate dehydrogenase $(L D H)$ assays. The activities of SOD and LDH were detected using SOD (cat. no. A001-3-2; Nanjing Jiancheng Bio-engineering Institute Co., Ltd.) and LDH assay kits (cat. no. A020-2; Nanjing Jiancheng Bio-engineering Institute Co., Ltd.). The protein extracts were incubated with working solutions according to the manufacturer's protocols and then the absorbance was measured with a multimode reader at $405 \mathrm{~nm}$.

CCK-8 assay. Cell viability was detected using a CCK-8 assay kit (cat. no. CK04; Dojindo Molecular Technologies, Inc.). NRK-52E cells were seeded in 96-well plates at a density of $2,000 /$ well. Following treatment with different concentrations of $\mathrm{NaBu}(0.1,0.5$ and $1 \mathrm{mM})$ at $37^{\circ} \mathrm{C}$ for $48 \mathrm{~h}, 10 \mu \mathrm{l} \mathrm{CCK}-8$ solution was added to each well and incubated at $37^{\circ} \mathrm{C}$ for $1 \mathrm{~h}$. The absorbance at $450 \mathrm{~nm}$ of each group was measured by a multimode reader (Thermo Fisher Scientific, Inc.).

Treatment with hydrogen peroxide $\left(\mathrm{H}_{2} \mathrm{O}_{2}\right)$ and $\mathrm{N}$-acetylcysteine $(N A C) . \mathrm{H}_{2} \mathrm{O}_{2}(200 \mu \mathrm{mol})$ or NAC $(5 \mathrm{mM})$ were added to NRK-52E cells with or without $\mathrm{NaBu}(0.5 \mathrm{mM})$ at $37^{\circ} \mathrm{C}$ for $48 \mathrm{~h}$.

Statistical analysis. Statistical analysis was conducted using SPSS version 22.0 (IBM Corp.). Data are expressed as the 
A

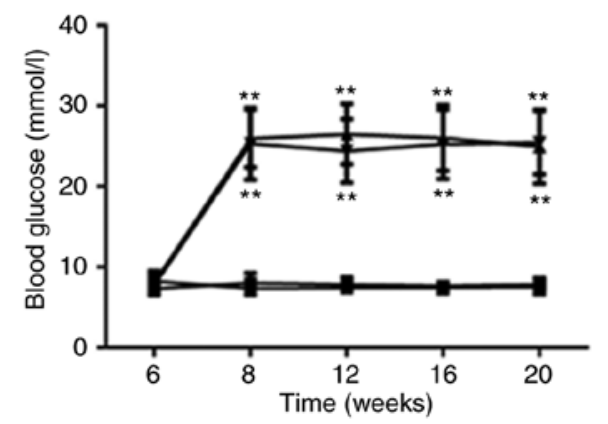

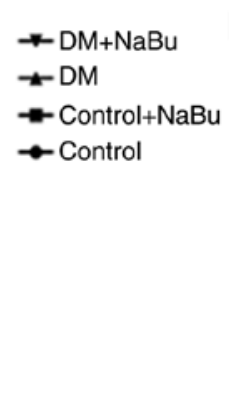
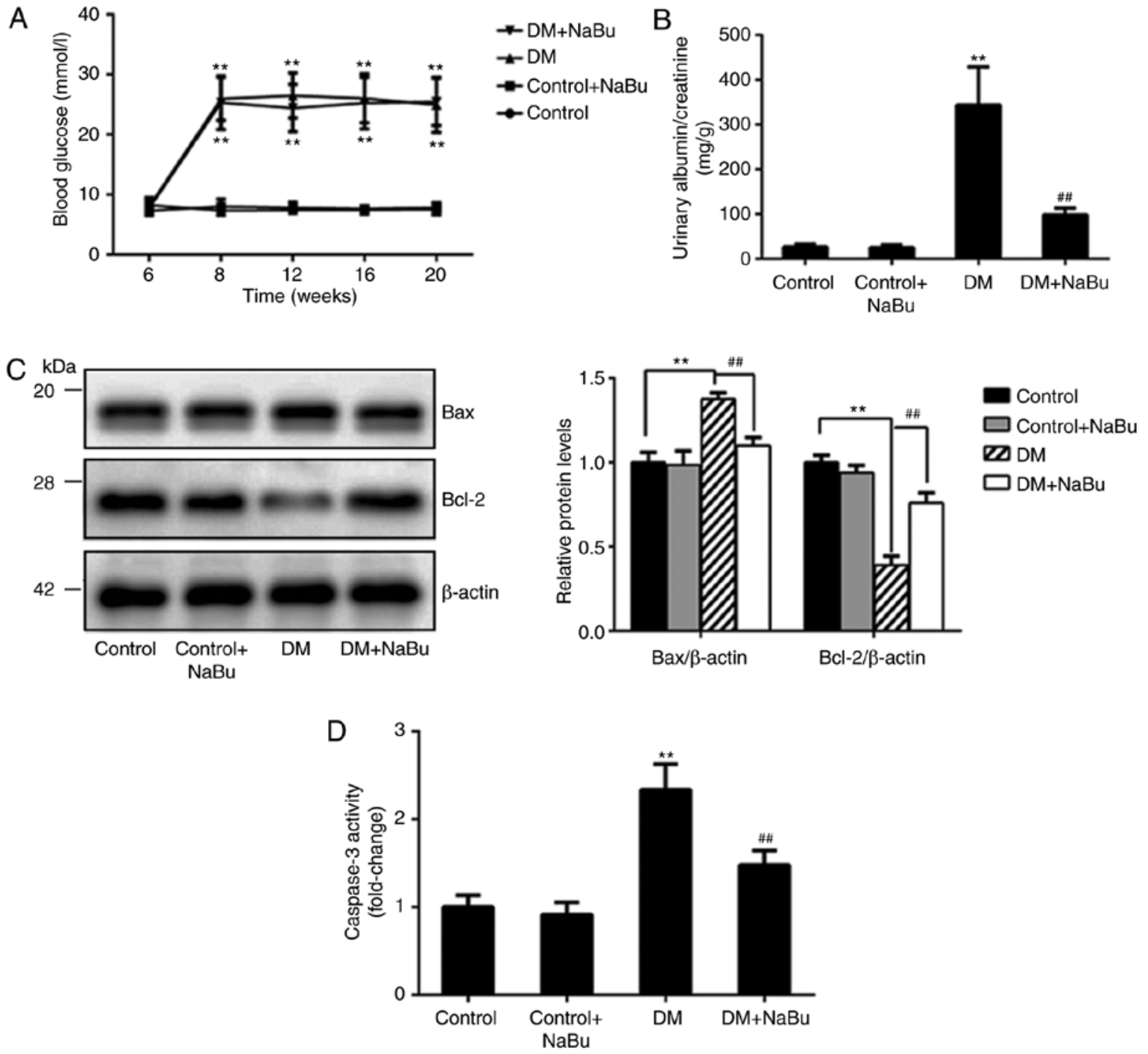

Figure 1. $\mathrm{NaBu}$ protects against renal cells apoptosis in $\mathrm{db} / \mathrm{db}$ mice. (A) Blood glucose levels in mice were monitored at $6,8,12,16$ and 20 weeks after birth. (B) Urinary albumin to serum creatinine ratio at week 20. (C) Expression of Bax and Bcl-2 in the kidney of mice measured by western blot analysis. (D) Caspase-3 activity in the kidney of mice. Data are presented as the means \pm standard deviation (control group, $\mathrm{n}=5$; control $+\mathrm{NaBu}$ group, $\mathrm{n}=5$; $\mathrm{DM}$ group, $\mathrm{n}=8 ; \mathrm{DM}+\mathrm{NaBu}$ group, $\mathrm{n}=12) .{ }^{* *} \mathrm{P}<0.01$ vs. control group; ${ }^{\# \#} \mathrm{P}<0.01$ vs. DM group. NaBu, sodium butyrate; DM, diabetic mellitus.

mean \pm standard deviation. Comparisons between two groups were analyzed with an independent Student's t-test. One-way ANOVA followed by the Student-Newman-Keuls post-hoc test was used to analyze the differences between multiple groups. $\mathrm{P}<0.05$ was considered to indicate a statistically significant difference.

\section{Results}

$\mathrm{NaBu}$ protects against renal cells apoptosis in $\mathrm{db} / \mathrm{db}$ mice. Due to the onset of diabetes, the mice in the DM and DM + $\mathrm{NaBu}$ groups developed significantly higher blood glucose levels from week 8 onwards compared with the control groups. $\mathrm{NaBu}$ had no effect on the blood glucose levels of diabetic mice (Fig. 1A). The ratio of urinary albumin/creatinine in the DM group was significantly higher compared with the ratio of the control group, as well as the $\mathrm{DM}+\mathrm{NaBu}$ group (Fig. 1B). Western blot analysis indicated that $\mathrm{HG}$ significantly upregulated Bax and downregulated Bcl-2 in the kidney of mice, while $\mathrm{NaBu}$ reversed these effects (Fig. 1C).
$\mathrm{NaBu}$ also significantly inhibited the activity of caspase-3 in diabetic kidneys (Fig. 1D). A significantly higher number of TUNEL-positive cells were observed in the DM group compared with the control group, while the $\mathrm{DM}+\mathrm{NaBu}$ group had significantly fewer TUNEL-positive cells compared with the DM group (Fig. 1E). The control + NaBu group exhibited no significant difference with the control group in the aforementioned indicators.

NaBu suppresses HG-induced NRK-52E cells apoptosis. Cell viability was detected by CCK- 8 assay. The results demonstrated that $\mathrm{NaBu}$ relieved the $\mathrm{HG}$-induced decrease in the viability of NRK-52E cells (Fig. 2A). In HG conditions, the activity of caspase-3 and expression of Bax in NRK-52E cells was significantly upregulated, while the expression of Bcl-2 was significantly downregulated (Fig. 2B and C). NaBu reversed the changes in apoptosis-related proteins induced by HG (Fig. 2B and C). The results of flow cytometry analysis further demonstrated that $\mathrm{NaBu}$ inhibited $\mathrm{HG}$-induced apoptosis of NRK-52E cells (Fig. 2D). The results of flow cytometry 
E

DAPI

Control+NaBu

DM

$\mathrm{DM}+\mathrm{NaBu}$
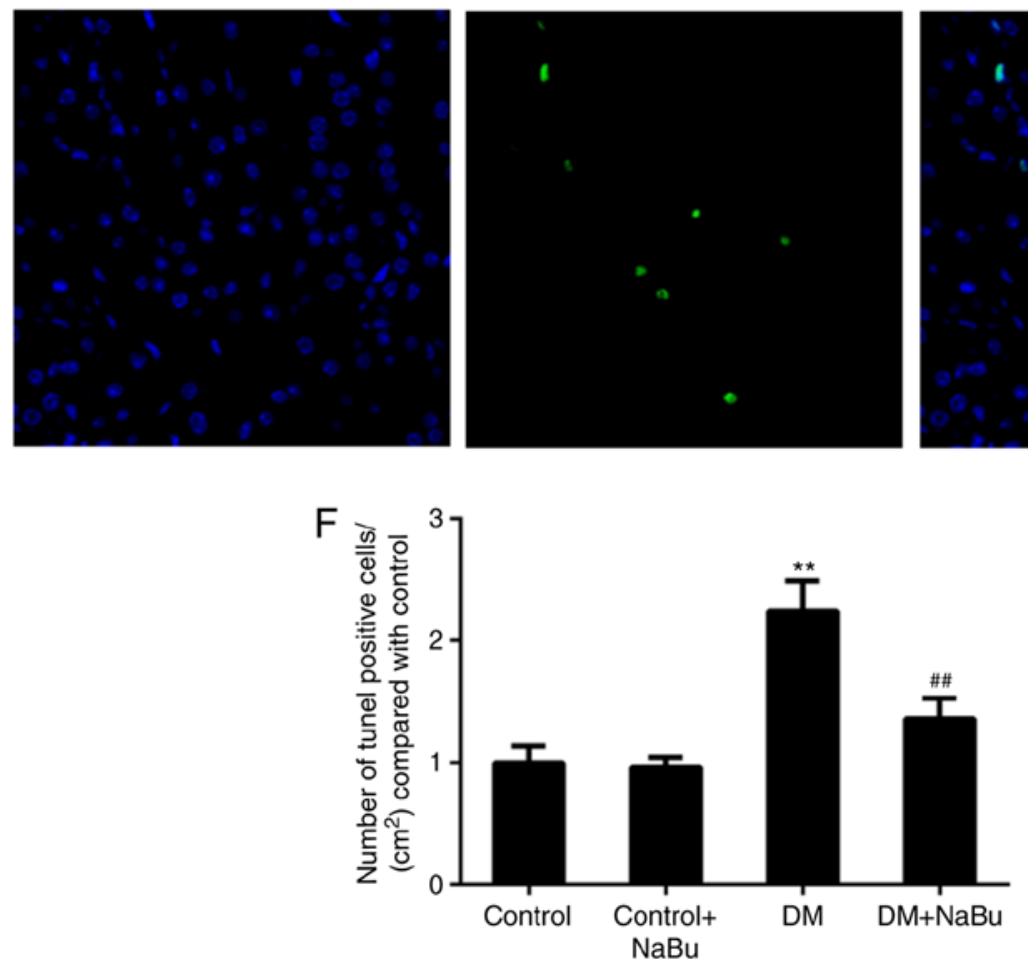

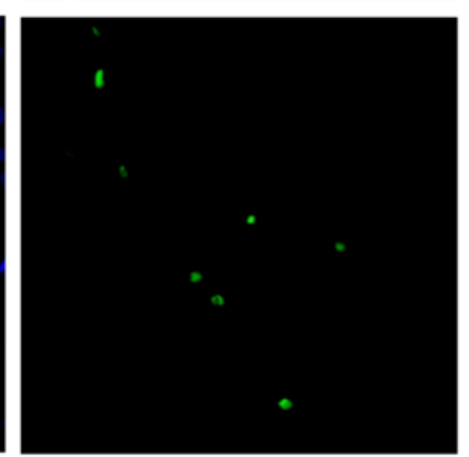

Tunel staining
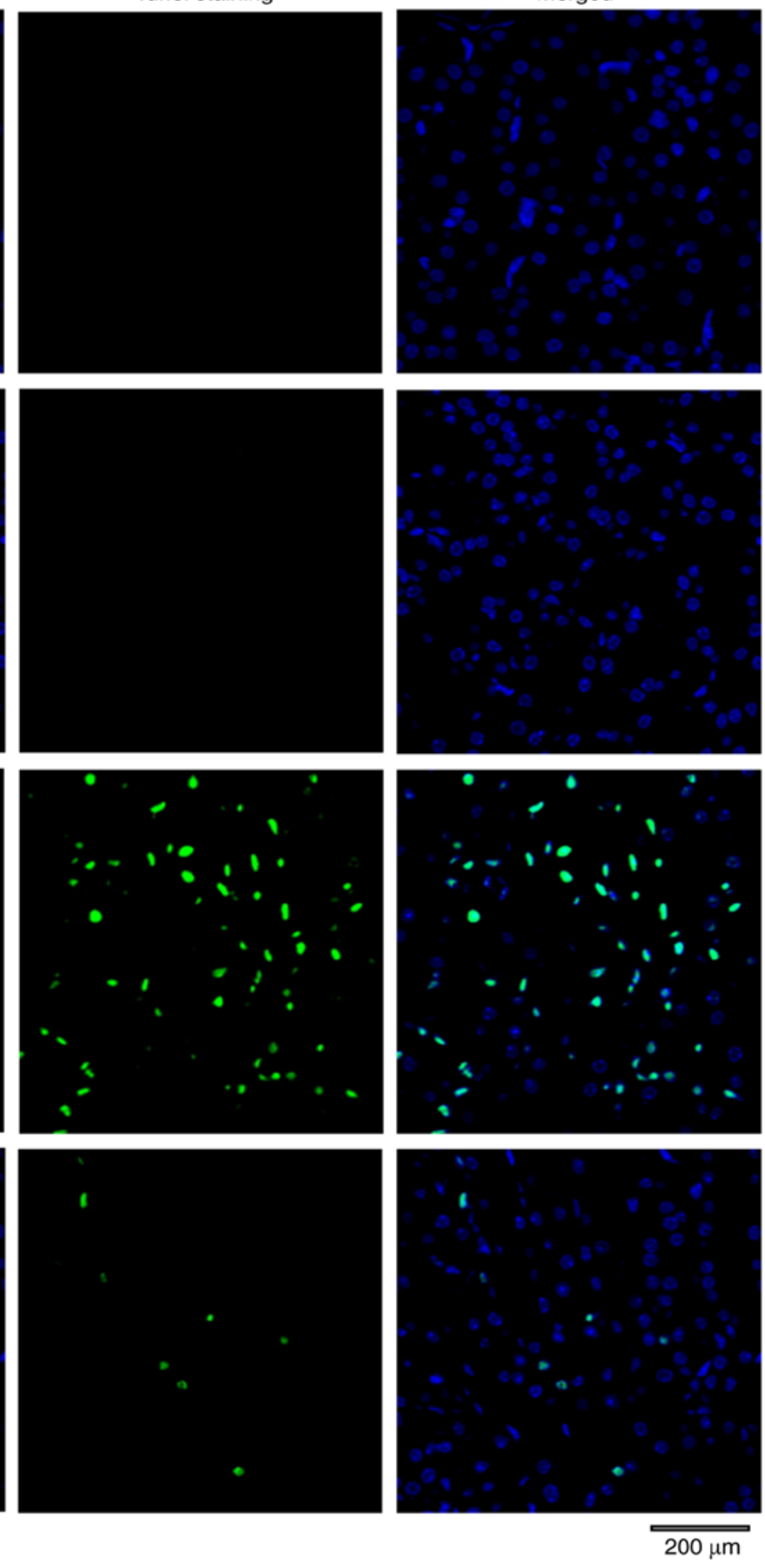

$200 \mu \mathrm{m}$
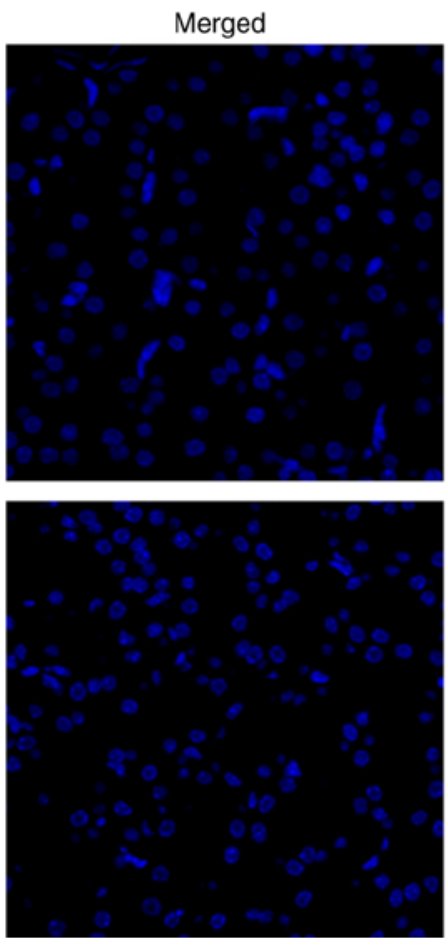

Figure 1. Continued. (E) Representative TUNEL staining image of renal sections in mice. (F) Numbers of TUNEL positive cells/ $\mathrm{cm}^{2}$ in different groups compared with the control. Scale bars, $200 \mu \mathrm{m}$. Data are presented as the means \pm standard deviation (control group, $\mathrm{n}=5 ;$ control $+\mathrm{NaBu}$ group, $\mathrm{n}=5 ; \mathrm{DM}$ group, $\mathrm{n}=8 ; \mathrm{DM}+\mathrm{NaBu}$ group, $\mathrm{n}=12) .{ }^{* *} \mathrm{P}<0.01$ vs. control group; ${ }^{\# \#} \mathrm{P}<0.01$ vs. $\mathrm{DM}$ group. $\mathrm{NaBu}$, sodium butyrate; DM, diabetic mellitus. 

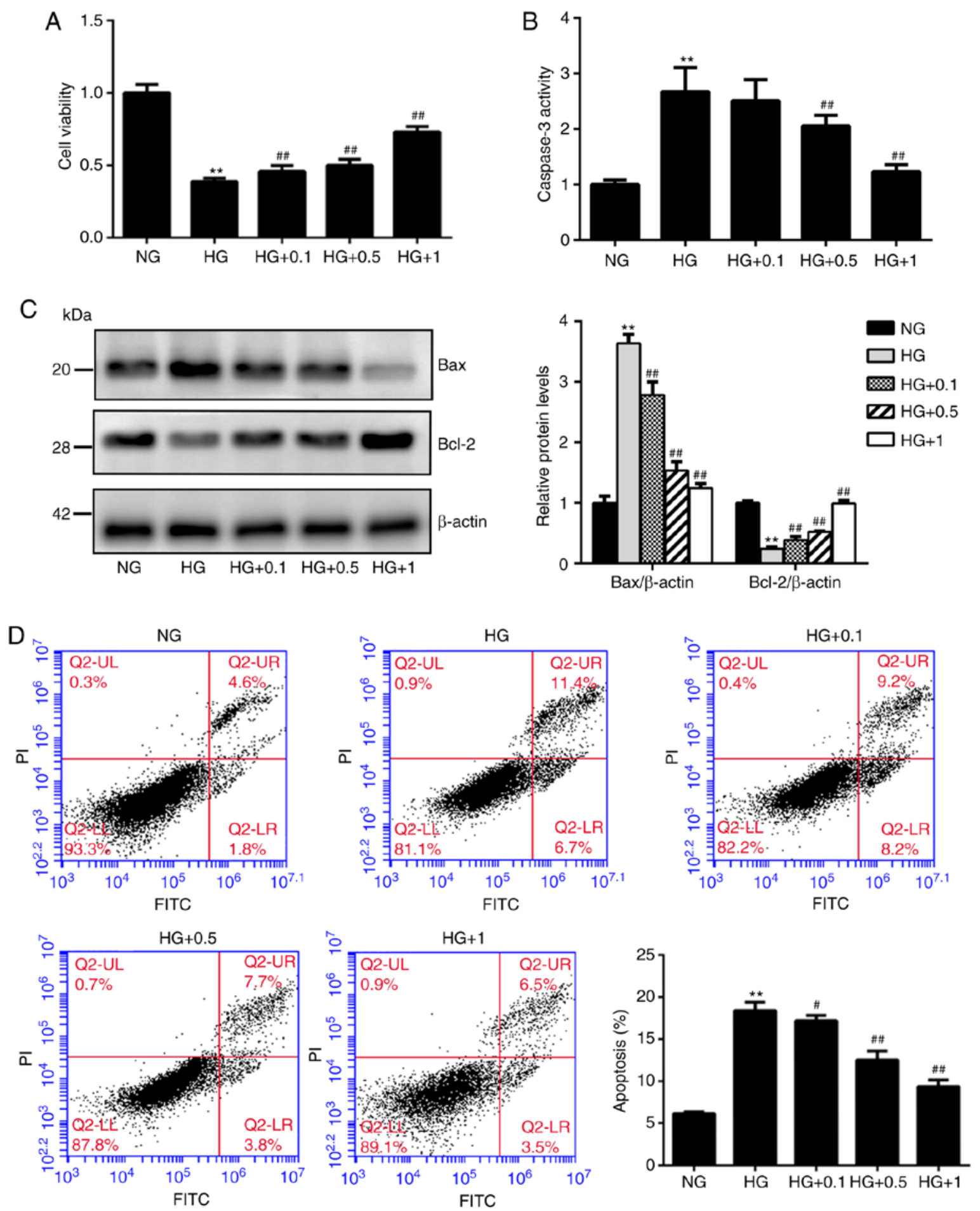

Figure 2. NaBu suppresses HG-induced NRK-52E cells apoptosis. (A) The influence of different concentrations of NaBu (0.1, 0.5 and $1.0 \mathrm{mmol} / \mathrm{l})$ on cell viability was detected by CCK8 assay. (B) Caspase-3 activity in different experimental groups. (C) Expression of Bax and Bcl-2 was analyzed by western blotting. (D) Flow cytometry analysis of apoptosis in NRK-52E cells. Cells in right upper quadrant were defined as late apoptotic cells, and cells in lower right quadrant were defined as early apoptotic cells. Cells in the above two quadrants were considered apoptotic cells. Data are presented as the mean \pm standard

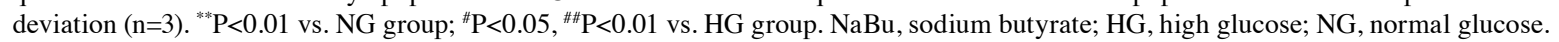

analysis also showed that with an increase of treatment time, the pattern of apoptosis of NRK-52E cells gradually changed from early apoptosis to late apoptosis (Fig. S1).

NaBu suppresses $H G$-induced NRK-52E cell apoptosis by inhibiting HDAC2. The present study found that additional $\mathrm{NaBu}$ significantly suppressed the increased activity of HDACs in HG-induced NRK-52E cells (Fig. S2A). TSA, a nonselective inhibitor of HDAC, inhibited the activity of caspase-3 and the expression of Bax, while it induced an upregulation of Bcl-2 compared with HG group (Fig. S2B and C). Flow cytometry analysis also demonstrated that TSA exhibited a similar anti-apoptotic function in HG-induced NRK-52E cells with $\mathrm{NaBu}$ (Fig. S2D). It was assumed that the anti-apoptotic 

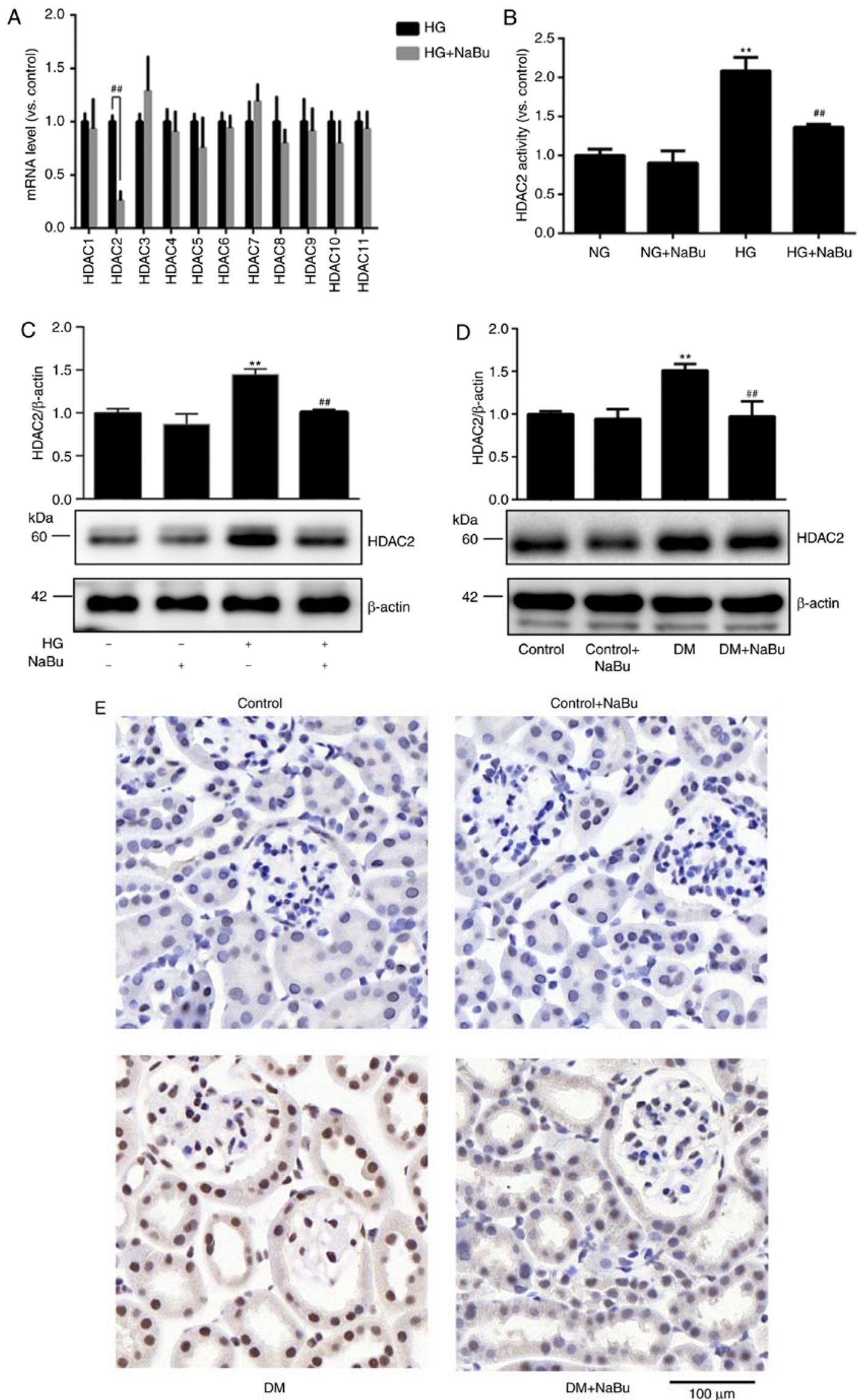

Figure 3. NaBu inhibits HG-induced upregulation of HDAC2 in vivo and in vitro. (A) NRK-52E cells were cultured under $\mathrm{HG}$ with or without NaBu (1 mM), and the mRNA expression of each subtype of HDACs was measured by RT-qPCR. (B) The activity of HDAC2 in NRK-52E cells. Western blot analysis of the expression of HDAC2 in (C) NRK-52E cells and (D) the kidney of db/db mice. (E) Representative images of immunohistochemistry analysis of HDAC2 in the kidney of $\mathrm{db} / \mathrm{db}$ mice (scale bar, $100 \mu \mathrm{m})$. Data are presented as the mean \pm standard deviation $(\mathrm{n}=3) .{ }^{* *} \mathrm{P}<0.01 \mathrm{vs}$. NG group; ${ }^{\# /} \mathrm{P}<0.01 \mathrm{vs}$. HG group. NaBu, sodium butyrate; HG, high glucose; NG, normal glucose; HDAC, histone deacetylase; RT-qPCR, reverse transcription-quantitative PCR; DM, diabetic mellitus. 

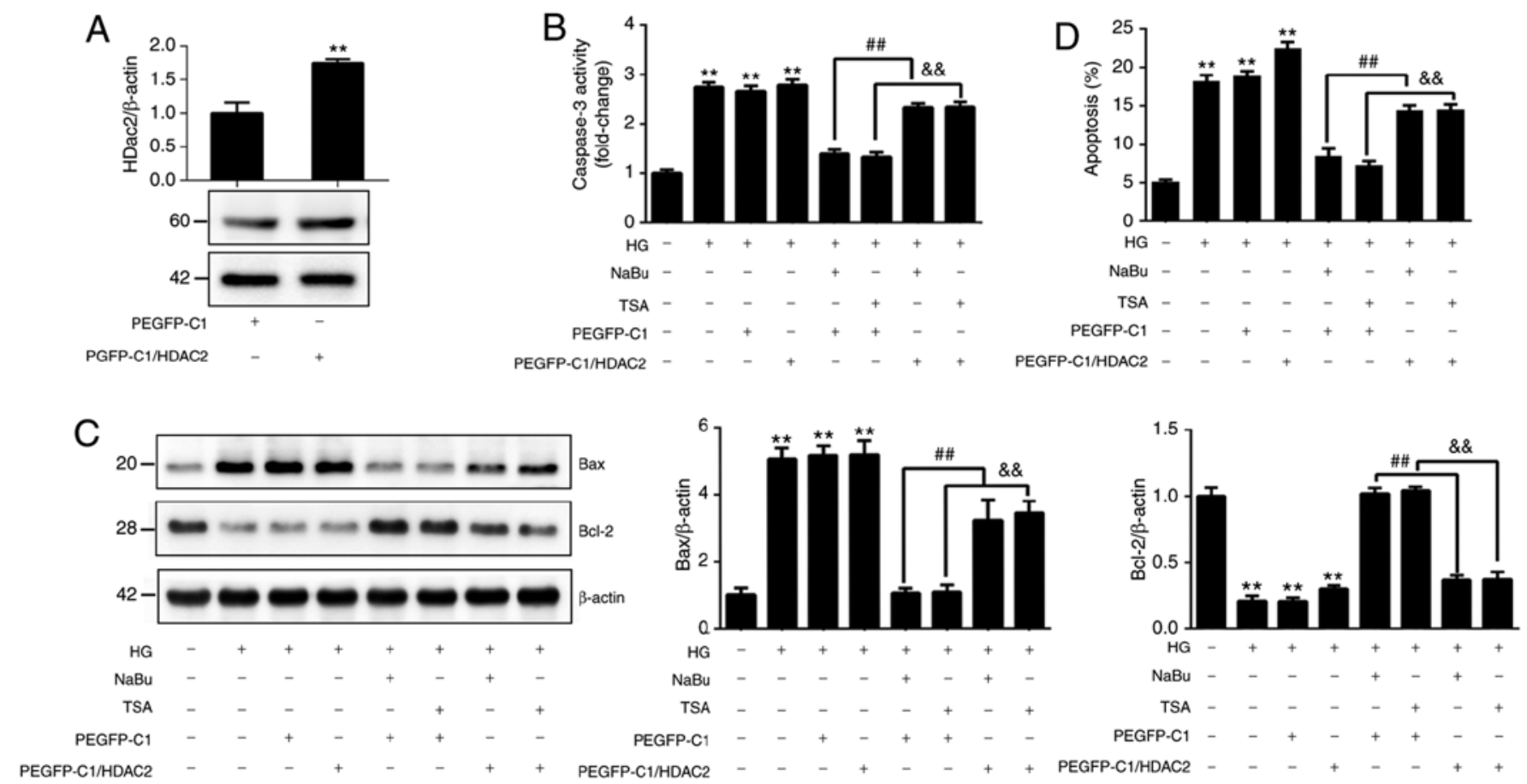

Figure 4. NaBu suppresses HG-induced apoptosis of NRK-52E cells by inhibiting HDAC2. (A) Effects of pEGFP-C1-HDAC2 on the expression of HDAC2 in NRK-52E cells cultured in DMEM with $5.5 \mathrm{mM}$ glucose. Effects of overexpression of HDAC2 on (B) the activity of caspase-3 and (C) the expression of Bax and Bcl-2. (D) Effects of overexpression of HDAC2 on the apoptosis of NRK-52E cells, as analyzed by flow cytometry. Data are presented as the mean \pm standard deviation $(n=3)$. ${ }^{* *} \mathrm{P}<0.01$ vs. NG group; ${ }^{\# \#} \mathrm{P}<0.01$; \&\& $\mathrm{P}<0.01$. NaBu, sodium butyrate; HG, high glucose; NG, normal glucose; HDAC, histone deacetylase; TSA, trichostatin A.

functions of $\mathrm{NaBu}$ in HG-stimulated NRK-52E cells were mediated by inhibition of HDACs.

Using RT-qPCR analysis it was identified that out of the eleven HDACs (HDAC1-11) studied, only the mRNA expression of HDAC2 was significantly attenuated by $\mathrm{NaBu}$ in NRK-52E cells with HG (Fig. 3A). Western blot analysis revealed that $\mathrm{NaBu}$ significantly suppressed the expression of HDCA2 in the kidneys of $\mathrm{db} / \mathrm{db}$ mice and HG-induced NRK-52E cells (Fig. 3C and D). In addition, NaBu significantly inhibited the activity of HDAC2 in HG-induced NRK-52E cells (Fig. 3B). The expression of HDAC2 was mainly concentrated in the nucleus. Through the immunohistochemical analysis, it was revealed that the staining of HDAC2 in the nuclei of DM group appeared more brown compared with the control and $\mathrm{DM}+\mathrm{NaBu}$ groups (Fig. 3E). These results indicated that $\mathrm{NaBu}$ inhibited the expression of HDAC2 in the kidney of $\mathrm{db} / \mathrm{db}$ mice as well as HG-induced NRK-52E cells.

To further understand the function of HDAC2 in the apoptosis of HG-induced NRK-52E cells, HDAC2 was overexpressed by transfecting NRK-52E cells with pEGFP-C1-HDAC2 (Fig. 4A). Over-expression of HDAC2 significantly suppressed the anti-apoptotic function of $\mathrm{NaBu}$ or TSA in HG-induced NRK-52E cells; caspase-3 activity and Bax expression were upregulated, while the expression of $\mathrm{Bcl}-2$ was downregulated compared with the cells transfected with a control plasmid (Fig. 4B and C). Similar results were observed by the flow cytometric analysis of apoptosis in different groups (Figs. 4D and S3).

$\mathrm{NaBu}$ suppresses the activity and the expression of HDAC2 by alleviating oxidative stress in HG-induced NRK-52E cells.
Previous studies have suggested that oxidative stress is associated with the activity of HDACs $(15,16)$. Oxidative stress has an important role in HG-induced apoptosis and the development of DN (17). The images of confocal microscopy revealed that compared with cells in the $\mathrm{HG}$ group, cells in the $\mathrm{HG}+\mathrm{NaBu}$ group exhibited darker DCF fluorescence (Fig. 5A), indicating that $\mathrm{NaBu}$ suppressed HG-induced production of ROS in NRK-52E cells. Similar results were observed by flow cytometry analysis (Fig. 5B). It was also identified that $\mathrm{NaBu}$ significantly suppressed the level of LDH but increased the level of SOD in HG-induced NRK-52E cells, which further demonstrated the antioxidant effect of $\mathrm{NaBu}$ (Fig. 5C and D). To study the relationship between ROS and HDAC2, normal NRK-52E cells were treated with $\mathrm{H}_{2} \mathrm{O}_{2}(200 \mu \mathrm{M})$, which resulted in a significant increase in the activity and expression of HDAC2 (Fig. 6A and B). Administering NAC (5 mM) to the cells under HG-treatment significantly inhibited the expression of HDAC2 but did not have a significant effect on the activity of HDAC2 (Fig. 6A and C). Additionally, $\mathrm{H}_{2} \mathrm{O}_{2}$ offset the inhibitory effect of $\mathrm{NaBu}$ on HDAC2 expression in NRK-52E cells (Fig. 6D). In conclusion, $\mathrm{NaBu}$ acted as an antioxidant in HG-induced NRK-52E cells and suppressed HG-induced apoptosis of NRK-52E cells via inhibiting HDAC2 by virtue of its anti-oxidative property (Fig. 7).

\section{Discussion}

Butyrate serves a protective role in diabetes and DN; however, the underlying mechanisms remain unclear. The present study focused on the effects and mechanisms of $\mathrm{NaBu}$ on the apoptosis of kidney cells in $\mathrm{db} / \mathrm{db}$ mice and HG-induced NRK-52E cells. 

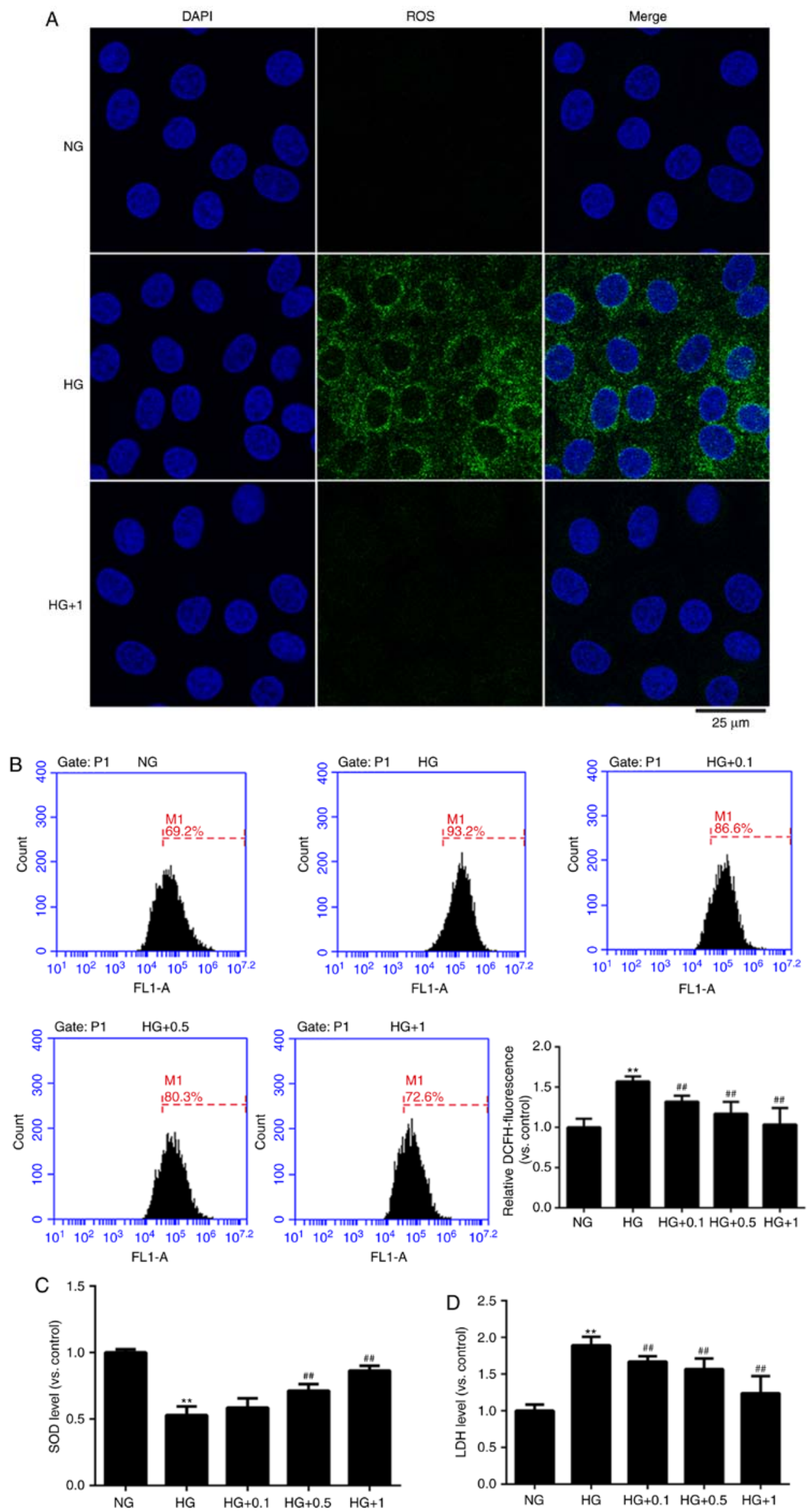

Figure 5. NaBu suppresses oxidative stress induced by HG in NRK-52E cells. (A) ROS in NRK-52E cells were detected by fluorescence signals using the DCFH-DA assay kit and imaged by confocal microscope. (B) ROS level was determined by flow cytometry. (C) SOD and (D) LDH level in NRK-52E cells. Scale bars, $25 \mu \mathrm{m}$. Data are presented as the mean \pm standard deviation $(\mathrm{n}=3) .{ }^{* *} \mathrm{P}<0.01 \mathrm{vs}$. NG group; ${ }^{\# \#} \mathrm{P}<0.01 \mathrm{vs}$. HG group. NaBu, sodium butyrate; HG, high glucose; NG, normal glucose; ROS, reactive oxygen species; SOD, superoxide dismutase; LDH, lactate dehydrogenase. 

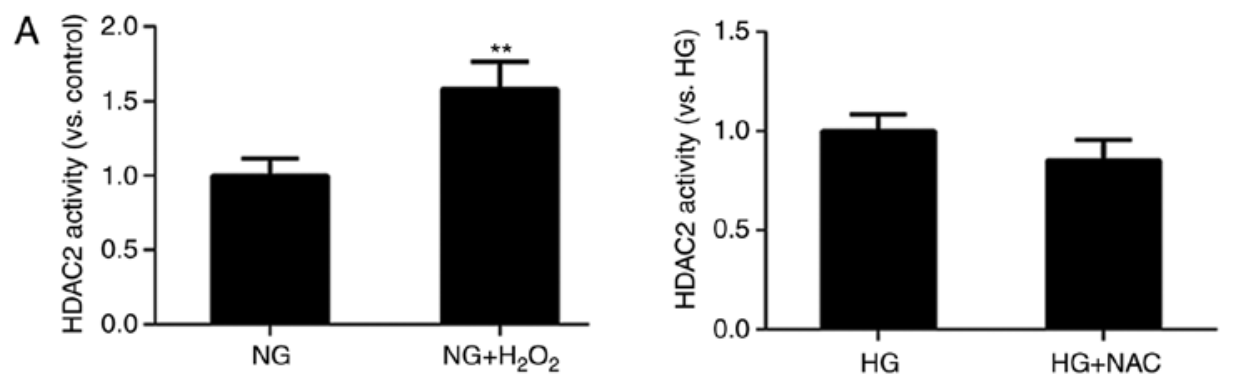

$\mathrm{B} \mathrm{kDa}$
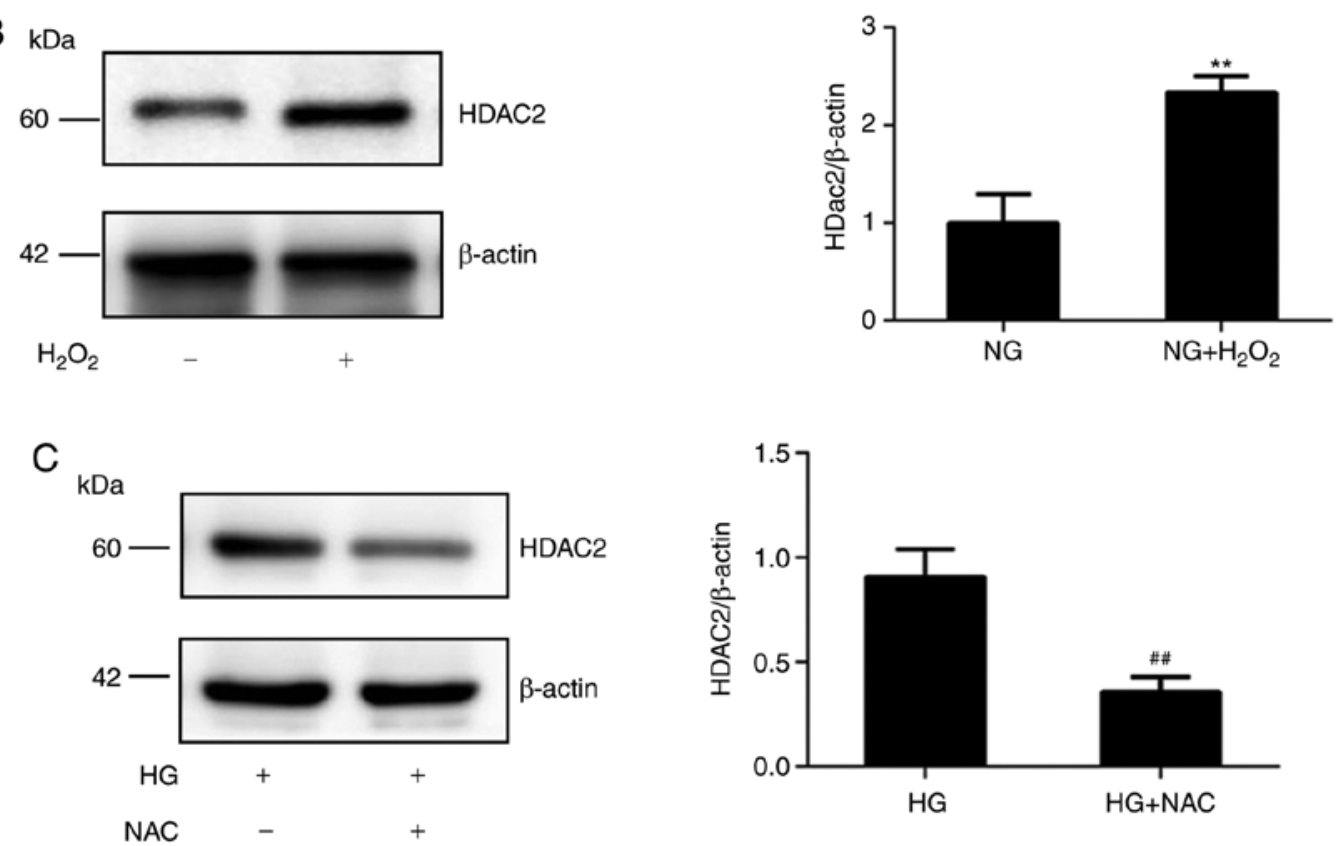

D
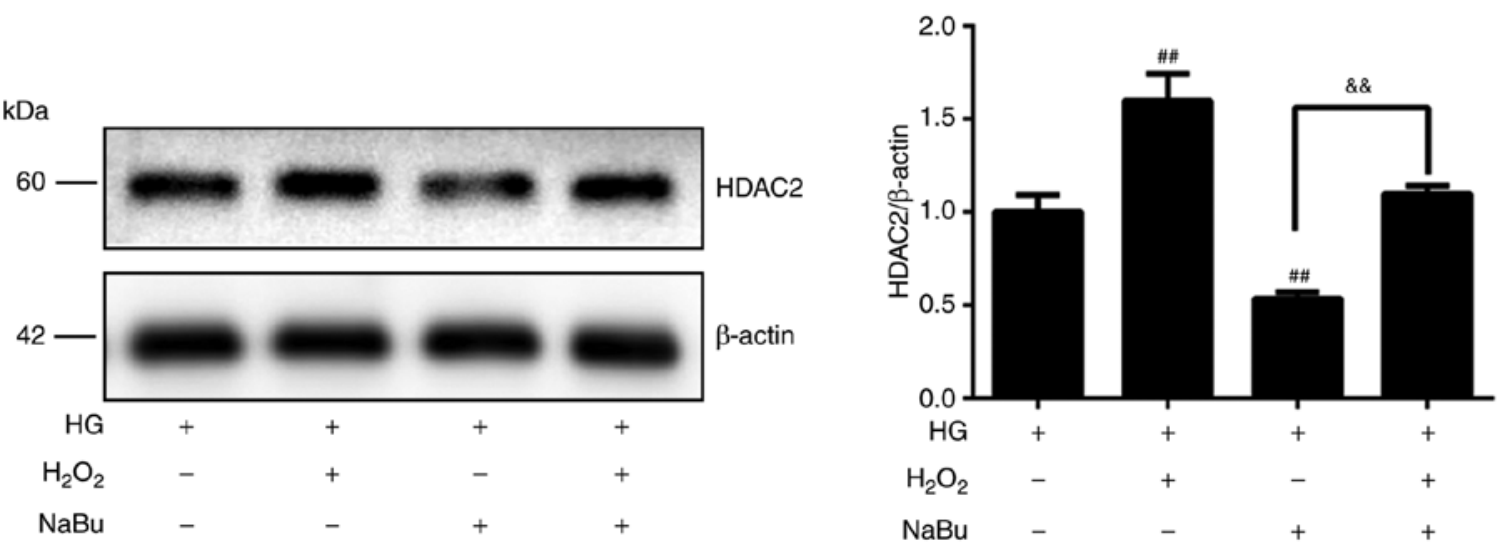

Figure 6. NaBu inhibits the expression of HDAC2 by alleviating oxidative stress. The effect of $\mathrm{H}_{2} \mathrm{O}_{2}(200 \mu \mathrm{M})$ on the (A) activity and (B) expression of $\mathrm{HDAC} 2$. The effect of NAC $(5 \mathrm{mM})$ on the (A) activity and (C) expression of HDAC2. (D) Effect of $\mathrm{NaBu}(1 \mathrm{mM}), \mathrm{H}_{2} \mathrm{O}_{2}(200 \mu \mathrm{M})$ or $\mathrm{NaBu}(1 \mathrm{mM})+\mathrm{H}_{2} \mathrm{O}_{2}(200 \mu \mathrm{M})$ on the expression of HDAC2 in HG-induced NRK-52E cells was determined by western blotting. Data are presented as the mean \pm standard deviation $(\mathrm{n}=3)$. ${ }^{* *} \mathrm{P}<0.01$ vs. NG group; ${ }^{\# /} \mathrm{P}<0.01$ vs. $\mathrm{HG}$ group; ${ }^{\& \&} \mathrm{P}<0.01$ vs. $\mathrm{HG}+\mathrm{NaBu}$ group. $\mathrm{NaBu}$, sodium butyrate; HDAC2, histone deacetylase $2 ; \mathrm{H}_{2} \mathrm{O}_{2}$, hydrogen peroxide; NAC, N-acetylcysteine; HG, high glucose; NG, normal glucose.

The findings revealed that $\mathrm{NaBu}$ relieved renal damage and apoptosis of kidney cells in $\mathrm{db} / \mathrm{db}$ mice. In vitro studies demonstrated that $\mathrm{NaBu}$ inhibited HG-induced apoptosis in NRK-52E cells by suppressing the activity and expression of HDAC2. In further experiments, it was revealed that $\mathrm{NaBu}$ inhibited the activity and expression of HDAC2 by alleviating oxidative stress.

NRK-52E cells were selected for in vitro evaluation of tubular injury in DN, as the extent of interstitial tubular injuries is closely related to the progression of $\mathrm{DN}$ (17). It has been reported that HG can activate the intrinsic apoptotic pathways in renal tubular epithelial cells, and the apoptosis-related proteins Bax, Bcl-2 and caspase-3 play crucial roles in this process $(18,19)$. Consistent with previous studies, the present study demonstrated that HG induced upregulation of the pro-apoptosis proteins Bax and caspase- 3 , and a downregulation of the anti-apoptosis proteins Bcl-2 in NRK-52E cells, which finally led to the apoptosis of cells. Additional use of $\mathrm{NaBu}$ alleviated this process. 


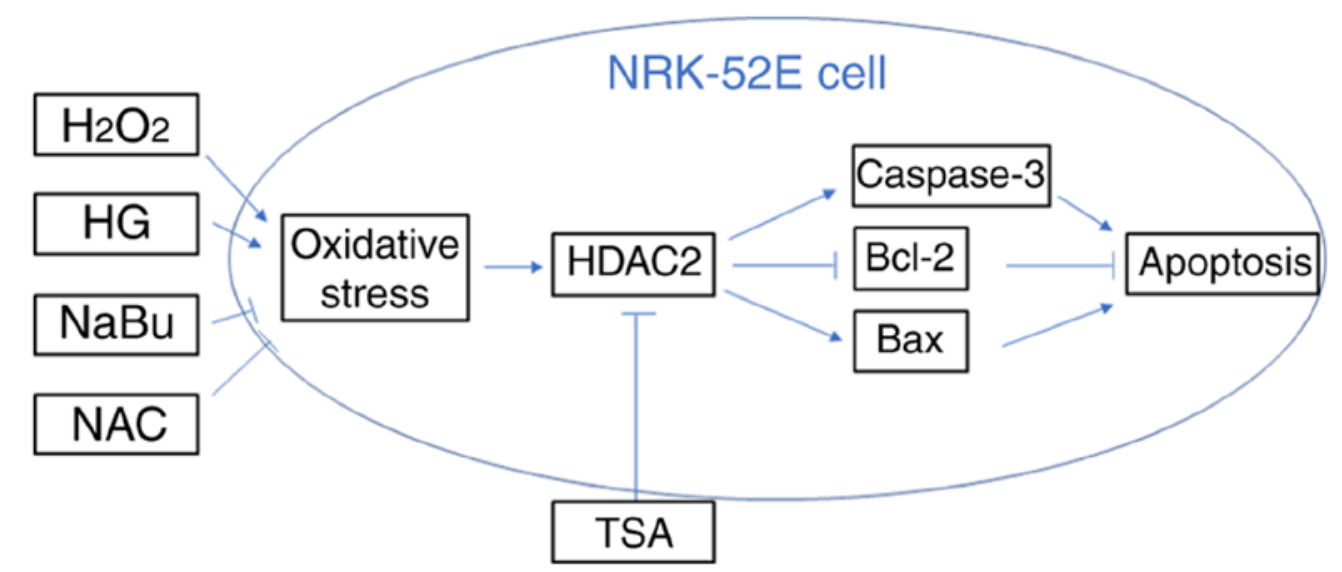

Figure 7. Anti-apoptotic mechanism of NaBu in HG-induced NRK-52E cells. The arrows indicate positive action and the other lines indicate negative action. $\mathrm{NaBu}$, sodium butyrate; $\mathrm{HG}$, high glucose; $\mathrm{H}_{2} \mathrm{O}_{2}$, hydrogen peroxide; $\mathrm{NAC}$, N-acetylcysteine; TSA, trichostatin A; HDAC, histone deacetylase.

Butyrate, propionate and acetate are major members of SCFAs. All have been reported to act as HDAC inhibitors, and butyrate has been investigated most extensively (20). Histone acetylation can promote gene transcription by increasing accessibility of the transcriptional system. HDAC inhibitors have been used for cancer therapy and suppressing inflammatory responses (21). Chang et al (22) reported that inhibiting HDAC6 attenuated intestinal apoptosis in a rodent model of hemorrhagic shock. HDAC inhibitors play an important role in diabetes treatment. Manea et al (23) demonstrated that HG increases the expression of HDAC1 and HDAC2 in human aortic smooth muscle cell in vitro, while HDAC inhibitor attenuates the structural and functional changes in the vascular wall in diabetes by inhibiting the formation of ROS. Another study suggested that HDAC inhibitor could cooperate with low-dose CD3 antibody to improve the survival and metabolic functions of pancreatic $\beta$ cells by inhibiting in situ inflammation, leading to alleviation of diabetes (24).

Previous studies have indicated that HDAC2 has a close relationship with kidney disease. Noh et al (25) reported that the kidneys of STZ-induced diabetic rats and $\mathrm{db} / \mathrm{db}$ mice have significantly increased activity of HDAC2. Furthermore, treatment with the HDACs inhibitor TSA or HDAC2-knockdown by small interfering RNA alleviates the TGF- $\beta 1$-induced epithelial-to mesenchymal transition in NRK-52E cells. Ma et al (26) found that the activity of HDAC2 in kidneys is elevated by cisplatin. TSA or valproic acid could alleviate cisplatin-induced kidney injury and epithelial cell apoptosis by inhibiting HDACs. The present study found that the expression of HDAC2 was significantly elevated in $\mathrm{db} / \mathrm{db}$ mice and HG-induced NRK-52E cells, which indicated that HDAC2 plays an important role in the development of DN.

As a common HDACs inhibitor, butyrate can inhibit most subtypes of HDACs, with the exception of class III HDAC and class II HDAC6 and 10 depending upon cell types and other external factors $(27,28)$. HDAC2 belongs to the class I HDAC. Butyrate has been reported to suppress HDAC2 activity in the liver and hippocampus in the brain $(29,30)$. The present study demonstrated that butyrate could inhibit the expression of HDAC2 in $\mathrm{db} / \mathrm{db}$ mice and HG-induced NRK-52E cells.
As a common HDACs inhibitor, TSA exhibited a similar anti-apoptotic function with $\mathrm{NaBu}$ in HG-induced NRK-52E cells. Overexpression of HDAC2 neutralized the anti-apoptotic function of $\mathrm{NaBu}$ and TSA. These results suggested that the anti-apoptotic function of NaBu in HG-induced NRK-52E cells was achieved by inhibiting HDAC2.

Previous studies have shown that butyrate can alleviate oxidative stress in certain situations. Administering $\mathrm{NaBu}$ can inhibit oxidative stress induced by high glucose and LPS in glomerular mesangial cells (27). In addition, butyrate can downregulate NADPH oxidase in endothelial cells and consequently decrease the oxidative stress in atherosclerotic lesion sites (31). Oxidative stress in the proximal colon of mice induced by chronic-binge ethanol feeding can also be inhibited by $\mathrm{NaBu}$ (32). The present study identified that $\mathrm{NaBu}$ suppresses HG-induced oxidative stress, inhibits the level of LDH and elevates the level of SOD in NRK-52E cells.

So far, the mechanism of $\mathrm{NaBu}$ in the regulation of HADC activity is not clear. Previous studies have indicated that oxidative stress may have a causal relationship with the activity of HDACs. Miura et al (16) reported that oxidative stress induced by hepatitis $C$ virus can increase HDACs activity and suppress hepcidin expression in hepatoma cell lines. Additionally, Niu et al (15) demonstrated that treating bronchial epithelial cells with $\mathrm{H}_{2} \mathrm{O}_{2}$ for $3 \mathrm{~h}$ lowered the histone acetylation markers $\mathrm{H} 3 \mathrm{~K} 9 \mathrm{ac}$ and $\mathrm{H} 4 \mathrm{~K} 8 \mathrm{ac}$, and increased the activity of class I/II HDAC. The present study found that additional $\mathrm{H}_{2} \mathrm{O}_{2}$ increased HDAC2 activity and the expression of HDAC2 in normal NRK-52E cells. While the anti-oxidative stress molecule $\mathrm{N}$-acetylcysteine (NAC) inhibited HDAC2 expression in HG-induced NRK-52E cells. In addition, $\mathrm{H}_{2} \mathrm{O}_{2}$ offset the inhibitory effect of $\mathrm{NaBu}$ on HDAC2 expression in NRK-52E cells, which indicated that $\mathrm{NaBu}$ influences the activity and expression of HDAC2 by regulating oxidative stress.

In summary, the present study discussed the anti-apoptotic effect and related mechanisms of $\mathrm{NaBu}$ in the kidney of $\mathrm{db} / \mathrm{db}$ mice and HG-induced NRK-52E cells. It was identified that $\mathrm{NaBu}$ acted as an antioxidant in HG-induced NRK-52E cells and the anti-oxidative property of $\mathrm{NaBu}$ was the basis of its anti-apoptotic effect. However, the specific mechanism 
of $\mathrm{NaBu}$ in regulating oxidative stress remains unclear and requires further investigation.

\section{Acknowledgements}

Not applicable.

\section{Funding}

This study was financially supported by the National Natural Science Foundation of China (grant no. 81700621).

\section{Availability of data and materials}

The datasets used and/or analyzed during the current study are available from the corresponding author on reasonable request.

\section{Authors' contributions}

YD performed the experiments, acquired and analyzed the data, and drafted the manuscript. GT searched relative literature and analyzed the data. WY designed the study and revised the manuscript. All authors read and approved the final manuscript.

\section{Ethics approval and consent to participate}

All animal-related experiments were approved by the Institutional Animal Care and Use Committee of Shanghai General Hospital and were in compliance with the Guide for the Care and Use of Laboratory Animals and the U.S. National Institutes of Health. The project number is 2019DW001.

\section{Patient consent for publication}

Not applicable.

\section{Competing interests}

The authors declare that they have no competing interests.

\section{References}

1. Shaw JE, Sicree RA and Zimmet PZ: Global estimates of the prevalence of diabetes for 2010 and 2030. Diabetes Res Clin Pract 87: 4-14, 2010

2. Sabatino A, Regolisti G, Cosola C, Gesualdo L and Fiaccadori E: Intestinal microbiota in type 2 diabetes and chronic kidney disease. Curr Diab Rep 17: 16, 2017.

3. Jaja-Chimedza A, Zhang L, Wolff K, Graf BL, Kuhn P, Moskal K, Carmouche R, Newman S, Salbaum JM and Raskin I: A dietary isothiocyanate-enriched moringa (moringa oleifera) seed extract improves glucose tolerance in a high-fat-diet mouse model and modulates the gut microbiome. J Funct Foods 47: 376-385, 2018

4. Koh GY and Rowling MJ: Resistant starch as a novel dietary strategy to maintain kidney health in diabetes mellitus. Nutr Rev 75: 350-360, 2017.

5. Cummings JH, Pomare EW, Branch WJ, Naylor CP and Macfarlane GT: Short chain fatty acids in human large intestine, portal, hepatic and venous blood. Gut 28: 1221-1227, 1987.

6. Andrade-Oliveira V, Amano MT, Correa-Costa M, Castoldi A, Felizardo RJ, de Almeida DC, Bassi EJ, Moraes-Vieira PM, Hiyane MI, Rodas AC, et al: Gut bacteria products prevent AKI induced by ischemia-reperfusion. J Am Soc Nephrol 26: $1877-1888,2015$.
7. Machado RA, Constantino Lde S, Tomasi CD, Rojas HA, Vuolo FS, Vitto MF, Cesconetto PA, de Souza CT, Ritter C and Dal-Pizzol F: Sodium butyrate decreases the activation of NF- $\kappa \mathrm{B}$ reducing inflammation and oxidative damage in the kidney of rats subjected to contrast-induced nephropathy. Nephrol Dial Transplant 27: 3136-3140, 2012.

8. Xu YH, Gao CL, Guo HL, Zhang WQ, Huang W, Tang SS, Gan WJ, Xu Y, Zhou H and Zhu Q: Sodium butyrate supplementation ameliorates diabetic inflammation in $\mathrm{db} / \mathrm{db}$ mice. J Endocrinol 238: 231-244, 2018.

9. Guo Y, Xiao Z, Wang YN, Wang Y, Yao W, Liao S, Yu B, Zhang J, Zhang Y, Zheng B, et al: Sodium butyrate ameliorates streptozotocin-induced type 1 diabetes in mice by inhibiting the HMGB1 expression. Front Endocrinol (Lausanne) 9: 630, 2018.

10. Khan S and Jena G: Sodium butyrate, a HDAC inhibitor ameliorates eNOS, iNOS and TGF- $\beta 1$-induced fibrogenesis, apoptosis and DNA damage in the kidney of juvenile diabetic rats. Food Chem Toxicol 73: 127-139, 2014.

11. Dong W, Jia Y, Liu X, Zhang H, Li T, Huang W, Chen X, Wang F, Sun $\mathrm{W}$ and $\mathrm{Wu} \mathrm{H}$ : Sodium butyrate activates NRF2 to ameliorate diabetic nephropathy possibly via inhibition of HDAC. J Endocrinol 232: 71-83, 2017.

12. Xiao L, Zhu X, Yang S, Liu F, Zhou Z, Zhan M, Xie P, Zhang D, Li J, Song P, et al: Rap1 ameliorates renal tubular injury in diabetic nephropathy. Diabetes 63: 1366-1380, 2014.

13. Livak KJ and Schmittgen TD: Analysis of relative gene expression data using real-time quantitative PCR and the 2(-Delta Delta C(T)) method. Methods 25: 402-408, 2001.

14. Aranda A, Sequedo L, Tolosa L, Quintas G, Burello E, Castell JV and Gombau L: Dichloro-dihydro-fluorescein diacetate (DCFH-DA) assay: A quantitative method for oxidative stress assessment of nanoparticle-treated cells. Toxicol In Vitro 27: 954-963, 2013.

15. Niu Y, DesMarais TL, Tong Z, Yao Y and Costa M: Oxidative stress alters global histone modification and DNA methylation. Free Radic Biol Med 82: 22-28, 2015.

16. Miura K, Taura K, Kodama Y, Schnabl B and Brenner DA: Hepatitis $C$ virus-induced oxidative stress suppresses hepcidin expression through increased histone deacetylase activity. Hepatology 48: 1420-1429, 2008.

17. Tong Y, Chuan J, Bai L, Shi J, Zhong L, Duan X and Zhu Y: The protective effect of shikonin on renal tubular epithelial cell injury induced by high glucose. Biomed Pharmacother 98: 701-708, 2018.

18. Allen DA, Harwood S, Varagunam M, Raftery MJ and Yaqoob MM: High glucose-induced oxidative stress causes apoptosis in proximal tubular epithelial cells and is mediated by multiple caspases. FASEB J 17: 908-910, 2003.

19. Wu H, Shi Y, Deng X, Su Y, Du C, Wei J, Ren Y, Wu M, Hou Y and Duan H: Inhibition of c-Src/p38 MAPK pathway ameliorates renal tubular epithelial cells apoptosis in $\mathrm{db} / \mathrm{db}$ mice. Mol Cell Endocrinol 417: 27-35, 2015.

20. Tan J, McKenzie C, Potamitis M, Thorburn AN, Mackay CR and Macia L: The role of short-chain fatty acids in health and disease. Adv Immunol 121: 91-119, 2014.

21. Lazarova DL and Bordonaro M: Vimentin, colon cancer progression and resistance to butyrate and other HDACis. J Cell Mol Med 20: 989-993, 2016.

22. Chang P, Bhatti UF, Williams AM, Dennahy IS, Liu B, Li Y and Alam HB: Inhibition of histone deacetylase 6 attenuates intestinal inflammation and apoptosis in a rodent model of hemorrhagic shock. J Trauma Acute Care Surg 86: 874-880, 2019.

23. Manea SA, Antonescu ML, Fenyo IM, Raicu M, Simionescu M and Manea A: Epigenetic regulation of vascular NADPH oxidase expression and reactive oxygen species production by histone deacetylase-dependent mechanisms in experimental diabetes. Redox Biol 16: 332-343, 2018.

24. Besançon A, Goncalves T, Valette F, Dahllöf MS, MandrupPoulsen T, Chatenoud L and You S: Oral histone deacetylase inhibitor synergises with $\mathrm{T}$ cell targeted immunotherapy to preserve beta cell metabolic function and induce stable remission of new-onset autoimmune diabetes in NOD mice. Diabetologia 61: 389-398, 2018.

25. Noh H, Oh EY, Seo JY, Yu MR, Kim YO, Ha H and Lee HB: Histone deacetylase-2 is a key regulator of diabetes- and transforming growth factor-betal-induced renal injury. Am J Physiol Renal Physiol 297: F729-F739, 2009. 
26. Ma T, Huang C, Xu Q, Yang Y, Liu Y, Meng X, Li J, Ye M and Liang H: Suppression of BMP-7 by histone deacetylase 2 promoted apoptosis of renal tubular epithelial cells in acute kidney injury. Cell Death Dis 8: e3139, 2017.

27. Davie JR: Inhibition of histone deacetylase activity by butyrate. J Nutr 133 (Suppl 7): 2485S-2493S, 2003.

28. Kim DS, Kwon JE, Lee SH, Kim EK, Ryu JG, Jung KA, Choi JW, Park MJ, Moon YM, Park SH, et al: Attenuation of rheumatoid inflammation by sodium butyrate through reciprocal targeting of HDAC2 in osteoclasts and HDAC8 in T cells. Front Immunol 9: 1525,2018

29. Singh $P$ and Thakur MK: Histone deacetylase 2 inhibition attenuates downregulation of hippocampal plasticity gene expression during aging. Mol Neurobiol 55: 2432-2442, 2018.

30. Zhou D, Chen YW, Zhao ZH, Yang RX, Xin FZ, Liu XL Pan Q, Zhou H and Fan JG: Sodium butyrate reduces high-fat diet-induced non-alcoholic steatohepatitis through upregulation of hepatic GLP-1R expression. Exp Mol Med 50: 157, 2018.
31. Aguilar EC, dos Santos LC, Leonel AJ, de Oliveira JS, Santos EA, Navia-Pelaez JM, da Silva JF, Mendes BP, Capettini LS, Teixeira LG, et al: Oral butyrate reduces oxidative stress in atherosclerotic lesion sites by a mechanism involving NADPH oxidase down-regulation in endothelial cells. J Nutr Biochem 34: 99-105, 2016.

32. Glueck B, Han Y and Cresci GAM: Tributyrin supplementation protects immune responses and vasculature and reduces oxidative stress in the proximal colon of mice exposed to chronic-binge ethanol feeding. J Immunol Res 2018: 9671919, 2018.

This work is licensed under a Creative Commons Attribution-NonCommercial-NoDerivatives 4.0 International (CC BY-NC-ND 4.0) License. 